\title{
Hidrelétricas na Bacia do Uruguai e a promoção do desenvolvimento regional
}

\author{
Humberto José da Rocha \\ Universidade Federal da Fronteira Sul - Erechim - RS - Brasil \\ ORCID: https://orcid.org/0000-0001-9943-9125
}

\begin{abstract}
Resumo
Este artigo tem por objetivo apresentar elementos para uma discussão sobre em que medida as usinas hidrelétricas de energia (UHE) promovem o desenvolvimento nas regiões onde são instaladas. $O$ estudo tem como referencial espaço-temporal a bacia hidrográfica do Uruguai, no Sul do Brasil, em que se destaca como objeto de análise a UHE Itá. Metodologicamente, o trabalho compreende uma sistematização de dados quantitativos compilados junto aos órgãos competentes, o que é complementado com análise qualitativa baseada em documentos oficiais e trabalhos acadêmicos. O texto está estruturado do seguinte modo: introdução; referencial teórico-metodológico ressaltando a importância da confluência de elementos econômicos, socioambientais e políticos para a análise; concepção de desenvolvimento, distinguindo as noções territorial, regional e local; complexidade das hidrelétricas enquanto projetos de grande escala; breve exercício com dados quantitativos de crescimento econômico e desenvolvimento humano; considerações finais relativizando dados quantitativos a partir de elementos qualitativos. No conjunto, o trabalho sustenta que as hidrelétricas têm capacidade de promover o desenvolvimento regional na medida em que elementos econômicos, políticos e socioambientais forem considerados de forma equilibrada desde a concepção do projeto.
\end{abstract}

Palavras-chave: Desenvolvimento regional. Hidrelétricas. Política. Economia. Ambiente.

\section{Hydroelectrics in the Uruguay Basin and the promotion of Regional Development Abstract}

This article aims to present elements for a discussion on the extent to which hydroelectric power plants (HPP) promote development in the regions where they are installed. The study has as its spatio-temporal reference the hydrographic basin of Uruguay, in the south of Brazil, in which the Itá HPP stands out as an object of analysis. Methodologically, the work comprises a systematization of quantitative data compiled with the competent bodies, which is complemented with qualitative analysis based on official documents and academic papers. The work is structured as follows: brief introduction; theoreticalmethodological framework highlighting the importance of the confluence of economic, socio-environmental and political elements for analysis; conception of development distinguishing territorial, regional and local notions; complexity of hydroelectric dams as large-scale projects; brief exercise with quantitative data on economic growth and human development; final considerations relativizing quantitative data from qualitative elements. Taken as a whole, the work argues that hydroelectric plants have the capacity to promote 
regional development insofar as economic, political and socio-environmental elements are considered in a balanced way since the project was conceived.

Keywords: Regional Development. Hydroelectric Plants. Politics. Economy. Environment.

\section{Las hidroeléctricas de la Cuenca del Uruguay y la promoción del desarrollo regional Resumen}

Este artículo tiene como objetivo presentar elementos para una discusión sobre la medida en que las centrales hidroeléctricas (HPP) promueven el desarrollo en las regiones donde están instaladas. El estudio tiene como referencia espacio-temporal la cuenca hidrográfica de Uruguay, en el sur de Brasil, en la que se destaca el HPP Itá como objeto de análisis. Metodológicamente, el trabajo comprende una sistematización de datos cuantitativos compilados con los organismos competentes, que se complementa con un análisis cualitativo basado en documentos oficiales y documentos académicos. El trabajo se estructura de la siguiente manera: breve introducción; marco teórico-metodológico que destaca la importancia de la confluencia de elementos económicos, socioambientales y políticos para el análisis; concepción del desarrollo que distingue nociones territoriales, regionales y locales; complejidad de las represas hidroeléctricas como proyectos a gran escala; breve ejercicio con datos cuantitativos sobre crecimiento económico y desarrollo humano; Consideraciones finales relativizando datos cuantitativos de elementos cualitativos. En su conjunto, el trabajo argumenta que las plantas hidroeléctricas tienen la capacidad de promover el desarrollo regional en la medida en que los elementos económicos, políticos y socioambientales se consideran de manera equilibrada desde que se concibió el proyecto.

Palabras clave: Desarrollo Regional. Plantas Hidroeléctricas. Política. Economía. Ambiente.

\section{Introdução}

A energia elétrica representa elemento crucial na discussão sobre o desenvolvimento. Considerando que o Brasil optou pela hidreletricidade como matriz predominante para a geração dessa energia, as usinas hidrelétricas de energia (UHE) representam Projetos de Grande Escala (PGE) concebidos em escala global para serem instalados em diferentes locais do planeta. Esse processo revela a complexidade da questão do desenvolvimento contrapondo concepções de desenvolvimento econômico e socioambiental na perspectiva regional. Com base nisso, este artigo tem como objetivo analisar essa complexidade no sentido de propor recortes analíticos que possibilitem discutir em que medida essas hidrelétricas podem promover o desenvolvimento nas regiões onde são instaladas.

O estudo tem como referência espaço-temporal a bacia hidrográfica do Uruguai, no Sul do Brasil, onde, ainda na década de 1960, se decidiu pela exploração sistemática da hidreletricidade. A questão será abordada tomando como objeto, sobretudo, a UHE Itá, que começou a ser construída na década de 1990 e entrou em operação no ano de 2000. A escolha por este caso se justifica metodologicamente em função do gigantismo da obra, das promessas e expectativas de desenvolvimento, dos acordos estabelecidos, da relocação do núcleo urbano e de diversas comunidades rurais, da localização em um rio limítrofe entre duas unidades da federação, do impacto sobre municípios com diferentes performances econômicas e da abrangência de uma série histórica considerável para a análise dos dados. A metodologia empregada segue as orientações de Lieberman (2005), autor 
que chama a atenção para o "valor sinérgico" das análises, mesclando métodos quantitativos e qualitativos. Os dados quantitativos foram compilados e sistematizados a partir do que apresentam os órgãos oficiais, sendo que a análise qualitativa é acrescida por pesquisa bibliográfica sobre trabalhos acadêmicos e documentos oficiais.

Para dar conta dos objetivos propostos segundo esse recorte espaçotemporal e metodológico, este trabalho está estruturado do seguinte modo: feita esta breve introdução, a segunda seção aborda a problemática de pesquisa, expondo as linhas gerais que balizam a discussão do ponto de vista teóricometodológico, destacando a interface entre elementos econômicos, socioambientais e políticos. A terceira seção enfatiza o recorte espaço-temporal, procurando distinguir e conferir operacionalidade às noções de desenvolvimento territorial, regional e local no debate sobre as hidrelétricas. A quarta seção assinala a especificidade da discussão sobre o desenvolvimento regional a partir das hidrelétricas, analisando como esses Projetos de Grande Escala (PGE) correspondem a "enclaves" que sobrepõem de forma específica as noções espaçotemporais, refletindo significativamente na abordagem - e, por que não, na promoção - do desenvolvimento regional. A quinta seção traz um breve exercício de análise dos dados quantitativos baseado em um caso específico. Finalmente, encaminhamos nossas considerações finais, ponderando esses dados através de elementos qualitativos que permitem relativizar a possibilidade de promoção do desenvolvimento regional a partir das hidrelétricas.

\section{Abordagem sobre a complexidade do desenvolvimento na contemporaneidade}

A discussão sobre as hidrelétricas e o desenvolvimento parte do que Ulrich Beck (2012) categoriza como "sociedade de risco" e, consequentemente, "modernização reflexiva". A ideia de sociedade de risco corresponde a "um estágio da modernidade em que começam a tomar corpo as ameaças produzidas até então no caminho da sociedade industrial" (BECK, 2012, p. 19). Isso se reflete em três aspectos relacionados: [1] a exaustão dos recursos naturais e culturais leva à [2] dificuldade de tomada de decisões envolvendo esses recursos, o que produz uma [3] condição de incerteza ante os riscos (BECK, 2012). Esse cenário leva à concepção de "modernização reflexiva", a qual, segundo o autor, embora sugira reflexão, implica, antes, autoconfrontação, propondo o enfrentamento dos efeitos da sociedade de risco, mencionados anteriormente, sem se prender aos parâmetros da sociedade industrial que os causa, mas procurando alternativas de como estes podem ser distribuídos, evitados, controlados e legitimados (BECK, 2012).

Os efeitos dessa sociedade de risco vão ao encontro do que Morin e Kern (2005) entendem como uma "tragédia do desenvolvimento". De acordo com os autores, essa tragédia se dá pelo fato de que o "mito global", segundo o qual "as sociedades industrializadas atingem o bem-estar, reduzem suas desigualdades extremas e dispensam aos indivíduos o máximo de felicidade que uma sociedade pode dispensar", é alimentado por uma "concepção redutora, em que o crescimento econômico é o motor necessário e suficiente de todos os desenvolvimentos sociais, psíquicos e morais" (MORIN; KERN, 2005, p. 78). Esse 
contraste resulta que "a noção de desenvolvimento se apresenta gravemente subdesenvolvida" (MORIN; KERN, 2005, p. 78).

Do ponto de vista teórico-metodológico, a perspectiva dialética se mostra interessante ao permitir compreender a dinâmica do desenvolvimento mediante duas ordens: a dos empreendedores e a das comunidades locais (BECKER, 2008a). A opção pelo método dialético significa não só diluir essas dicotomias em uma unidade de análise, como colocá-las frente a frente buscando razões e prevalências. Mais do que simples "contrariedade" entre duas lógicas, a "contraditoriedade" ou unicamente a contradição implica conceber o desenvolvimento atentando para o processo de transformação do homem, trabalho e ambiente em mercadorias de forma antagônica, beneficiando alguns em detrimento de outros, e progressiva, a qual, no limite, enxerga a reprodução do capital como um fim em si mesmo (BECKER, 2008b). Essa análise dialética precisa ser feita sob três ângulos: econômico, social e político. Eles se relacionam de modo que a economia abrange a articulação do capital global nos processos de desenvolvimento que acontecem em locais que sofrem transformações socioambientais, as quais, por sua vez, têm sua mediação feita politicamente (BECKER, 2008a).

Do panorama econômico, é importante a proposição da discussão para além do crescimento. O crescimento econômico, analisado a partir do Produto Interno Bruto (PIB), é questionado por Celso Furtado (1974) ainda na década de 1970, quando o autor indaga que esse índice, ao ignorar o custo da destruição dos recursos naturais e os baixos salários, questões que geram o desgaste humano, se torna um "conceito ambíguo, amálgama considerável de definições mais ou menos arbitrárias", que acaba sustentando o "mito do desenvolvimento econômico" (FURTADO, 1974, p. 117-118).

Na mesma linha, Amartya Sen (2010, p. 20) defende que "ser genericamente contra os mercados seria quase tão estapafúrdio quanto ser genericamente contra a conversa entre as pessoas". Embora reconheça o papel importante do mercado, o autor assinala que "o principal é que o impacto do crescimento econômico depende muito do modo como seus frutos são aproveitados” (SEN, 2010, p. 66). Tanto Furtado (1974) quanto Sen (2010) mencionam dados de mortalidade infantil e expectativa de vida como aspectos interessantes para a análise do desenvolvimento. O Índice de Desenvolvimento Humano (IDH) como instrumento metodológico permite indicar possíveis efeitos do desenvolvimento em determinada sociedade. Ao considerar saúde, educação e renda per capita, o IDH oferece referências mais completas para a análise sobre certa região. Em se tratando de hidrelétricas enquanto Projetos de Grande Escala, o aumento do PIB é importante, mas precisa ser tomado como ponto de partida e não um fim em si mesmo, ao passo que o IDH fornecerá elementos que podem ser tomados como referência ou reflexo desses projetos.

Indicadores como PIB e IDH, embora sirvam tanto para pesquisa de viabilidade quanto de efetividade dos projetos, merecem ser analisados sob a luz do que Fernández (2004) chama de um "triângulo estratégico" para a análise do desenvolvimento regional, formado pelos conceitos de "densidade institucional", "cadeias de valor" e "inovação territorial". Segundo o autor, a densidade institucional compreende os agentes envolvidos em dado projeto em uma dada região; as cadeias de valor se referem às atividades envolvidas em todo o projeto; e 
a inovação territorial seria o conjunto desses agentes e atividades no sentido de um sistema dinâmico que caracteriza e especifica determinado território em um processo de desenvolvimento (FERNÁNDEZ, 2004). Então, mapear os agentes e atividades de forma a vislumbrar esse sistema é metodologicamente fundamental para um recorte analítico sobre desenvolvimento regional.

O estudo do desenvolvimento regional a partir de índices de PIB e IDH em interface com o triângulo, ainda que permita um panorama da região em questão, precisa ser acompanhado de elementos do campo político, sob pena de quedar demasiadamente estruturalista. Para tanto, são essenciais os conceitos de "democracia", "capital social" e "empoderamento". Ante a complexidade do termo democracia, Norberto Bobbio (2000, p. 30) apresenta uma definição que ele próprio reconhece como "mínima", "caracterizada por um conjunto de regras que estabelecem quem está autorizado a tomar as decisões coletivas e com quais procedimentos".

Na discussão sobre desenvolvimento a partir de Projetos de Grande Escala, esse conceito reforça a importância da institucionalização da discussão, recorrente nesses casos. Essa institucionalização em diferentes regiões de análise é mais bem percebida em seus condicionantes e efeitos através da utilização do conceito de capital social. Nesse sentido, Putnam (2006, p. 177) afirma que o capital social compreende as "características da organização social, como confiança, normas e sistemas, que contribuam para aumentar a eficiência da sociedade, facilitando as ações coordenadas". Nesses termos, o entendimento do nível de capital social de determinada sociedade nos ajuda a conceber a dinâmica da densidade institucional referida anteriormente. A ideia de "empoderamento" vai ao encontro das duas primeiras (democracia e capital social) para reforçar a natureza endógena do desenvolvimento. Considerando que o termo pode se referir tanto à delegação quanto à emancipação (GOHN, 2004) ou mesmo pode ocorrer em nível individual, organizacional ou coletivo (BAQUERO, 2012), o principal é ter em vista o empoderamento enquanto incremento da participação efetiva dos vários grupos, especialmente os mais fracos, na tomada de decisões sobre assuntos que vão incidir diretamente sobre a sua qualidade de vida.

Em síntese, a complexidade da sociedade atual propõe uma análise sob a luz de uma situação de risco em que o desenvolvimento não represente a exaustão dos recursos naturais e não reflita apenas no crescimento econômico. Os critérios desse desenvolvimento podem ser analisados a partir de dados quantitativos (PIB e IDH) que evoluem qualitativamente à medida que são mesclados com dados de um triângulo estratégico, os quais, por sua vez, são entendidos segundo seus níveis de democracia, capital social e empoderamento. Dessa forma, têm-se linhas gerais de uma análise dialética que vai na direção do que propõe Amartya Sen (2010). O referido autor conscientemente começa seu texto reconhecendo ser "estapafúrdia" a ideia de rejeitar o mercado nas abordagens sobre desenvolvimento, mas, de forma não menos eloquente, termina o mesmo texto defendendo que essas abordagens "não podem realmente concentrar-se tanto apenas nos detentores do poder” (SEN, 2010, p. 317). 


\section{Um recorte espaço-temporal para discussão do desenvolvimento envolvendo hidrelétricas}

Apresentados os conceitos teórico-metodológicos gerais, passamos para o recorte espaço-temporal sobre o desenvolvimento. A importância desse recorte está no fato de que, em um cenário em que "cada lugar é, à sua maneira, o mundo" ao mesmo tempo que "irrecusavelmente imerso numa comunhão com o mundo, torna-se exponencialmente diferente dos demais", sugerindo uma ideia de "glocalidade" (SANTOS, 2004, p. 213), é importante distinguirmos com maior clareza nosso conceito de desenvolvimento territorial, regional e local.

Milton Santos (2004) sugere que podem ser admitidos três níveis de espaço, que se confirmam e se contradizem mutuamente. De maneira genérica, o autor introduz o "nível mundial ou global", que se refere ao planeta; "o nível dos territórios dos Estados", que se refere aos países; e o nível "local”, onde os outros dois níveis tendem a ocorrer de forma condizente com cada especificidade. Adequando as ideias do autor aos objetivos deste trabalho, evidenciam-se os níveis espaciais recorrendo à noção de "escala", a qual precisa ser considerada em sentido duplo: [1] quanto à "origem", fazendo alusão à demanda de determinada ação, ou seja, em que parte do espaço se concebeu essa ação; e [2] quanto à "ocorrência", ou seja, em que parte do espaço essa ação vai ser empreendida, sendo que esse local precisa considerar, além do fator espacial, relativo à área de ocorrência, o fator temporal, relativo à variação dos efeitos ao longo do tempo (SANTOS, 2004).

Disto, propomos a organização do espaço em quatro níveis, acrescentando o nível regional, o que ajudará na especificidade da conceituação de desenvolvimento. O nível global concerne às ações que poderão influenciar sociedades locais, mas que são tomadas por agentes que se comportam de forma desterritorializada espacialmente. Ações de agentes como o Banco Mundial são exemplos disso, pois, através de seus relatórios e proposições, baseados em diferentes casos espalhados pelo globo, influenciam as ações locais. O nível nacional não desconsidera o nível anterior; porém, é adequado às normas de um território que precisa ser compreendido em sua especificidade política, jurídica, econômica, ambiental, social e cultural. Aqui as ações dos Estados e das legislações dos países são aspectos preponderantes. O nível regional tem sua importância dadas a extensão territorial e a heterogeneidade cultural do Brasil. Não obstante a relevância da regionalização política, econômica e cultural, merece destaque a organização da hidrografia brasileira segundo regiões hidrográficas, a qual, a partir do aspecto ambiental, sobretudo o fluvial, é importante para o tratamento da questão hídrica, pois seria difícil entender o tema na bacia do rio Uruguai tomando como base as características amazônicas, por exemplo. O nível local diz respeito àquelas especificidades de uma região. Sendo que tomamos a bacia do rio Uruguai como região, temos uma variação de condições que tornam o Alto Uruguai distinto do Baixo Uruguai, por exemplo. Apesar de restritos a uma mesma bacia hidrográfica, é preciso distinguir os locais para que não tratemos de problemas específicos de certo local com base em generalizações regionais que nem sempre correspondem à totalidade dessa região, muito menos às diferentes realidades locais (CHRISTOFOLETTI, 1979). 
A categorização do espaço em quatro níveis não pretende compartimentar a análise, e sim ajudar na compreensão de categorias de desenvolvimento endógeno e exógeno, que, grosso modo, sugerem respectivamente o controle interno e externo das ações de desenvolvimento tendo como referência determinado território (BOISIER, 2000). Segundo Moraes (2008), o desenvolvimento endógeno vai ao encontro da ideia de desenvolvimento "de baixo para cima”. Entretanto, essa proposta, que se aproxima do empoderamento mencionado anteriormente, precisa ser analisada considerando o território como "um sistema que sofre influência de variáveis internas e interage com sistemas territoriais de maior escala" (MORAES, 2008, p. 270). Assim, faz-se importante a distinção entre desenvolvimento territorial, regional e local na perspectiva de análise dos Projetos de Grande Escala.

Sobre o "desenvolvimento territorial", Boisier (2000, p. 159-160) afirma se referir "à escala geográfica de um processo e não à sua substância". Na mesma linha das ideias de Milton Santos (2004), o autor explica que o "território natural" (objetos) dá suporte para o reconhecimento do "território equipado" (pela ação do homem), o qual, de forma processual (tempo), pode então se tornar um "território organizado", mais complexo em decorrência do seu ordenamento administrativo (jurídico, mercantil, social). Considerando a noção de escala, ainda é possível reconhecer diferentes recortes para o conceito, a dizer: "mundo, continente, país, região, estado, província, departamento, comuna, veredas ou mesmo categorias menores" (BOISIER, 2000, p. 160).

Embora o território implique territorialização, esse sentido cultural de apropriação e reconhecimento entre o homem e o território tende a configurar ações jurídico-administrativas sobre espaço corroboradas através do Estado. Haja vista o recorte espacial deste trabalho, além da organização político-administrativa do Brasil, Rio Grande do Sul e Santa Catarina, são exemplares as organizações por meio dos Conselhos Regionais de Desenvolvimento (Coredes) ${ }^{1}$ no Rio Grande do Sul e das Agências de Desenvolvimento Regional (ADRs) ${ }^{2}$ em Santa Catarina. Ambos se orientam pela lógica estatal acrescida de relações no âmbito da sociedade civil no sentido de integrar, sobretudo, interesses e esforços econômicos, reorganizando o território mediante ações para o desenvolvimento.

O "desenvolvimento regional" remete a uma ideia subjetiva em relação ao desenvolvimento territorial. Boisier (2000, p. 160) sintetiza declarando que "o desenvolvimento regional consiste em uma mudança estrutural localizada em um âmbito territorial denominado região". Isso assinala a interdependência entre os termos; por outro lado, distingue-os, atribuindo ao território um recorte jurídico mais preciso, ao passo que a região é mais flexível do ponto de vista metodológico. Essa concepção vai ao encontro do que defende Milton Santos (2004, p. 108) ao afirmar que "a região e o lugar não têm existência própria. Nada mais são que uma

\footnotetext{
${ }^{1}$ Os Conselhos Regionais de Desenvolvimento foram criados pela Lei $n .^{\circ} 10.283$, de 17 de outubro de 1994, e regulamentados pelo Decreto . $^{\circ} 35.764$, de 28 de dezembro de 1994. O Conselho tem foro jurídico na comarca em que reside seu presidente e sede política em todos os municípios que o integram. O funcionamento ocorre através da deliberação, em reuniões plenárias realizadas em caráter ordinário ou extraordinário, sobre temas de interesse regional.

${ }^{2}$ Reestruturadas a partir das antigas Secretarias de Estado de Desenvolvimento Regional (SDR), as Agências de Desenvolvimento Regional (ADRs) foram criadas pela Lei n. ${ }^{0} 16.795$, de 16 de dezembro de 2015 .
} 
abstração, se os considerarmos à parte da totalidade". Essa abstração se transforma de acordo com o "movimento histórico" dos "recursos totais do mundo ou de um país, quer seja o capital, a população, a força de trabalho, o excedente etc., dividem-se pelo movimento da totalidade, através da divisão do trabalho e na forma de eventos" (SANTOS, 2004, p. 108). Na mesma linha, Boisier (2000, p. 161) sumariza que falar em desenvolvimento regional implica a "própria complexidade de um sistema aberto".

A subjetividade inerente ao desenvolvimento regional significa que o recorte metodológico pode ser feito segundo referenciais naturais, culturais ou até de aptidões econômicas específicas de determinada parte do espaço. Isso se intensifica na temática das hidrelétricas pelo fato de que tanto a regionalização feita a partir da hidrografia latino-americana quanto a organização territorial proposta pela Agência Nacional de Águas (ANA), sob a qual atuam os Comitês de Bacias Hidrográficas $(\mathrm{CBH})$, servem como exemplos do recorte de região que se sobrepõe à organização territorial apresentada anteriormente de acordo com os Coredes e ADRs. Observando as Figuras 1 e 2 a seguir, é possível perceber que, ao passo que a bacia do Prata drena cinco países na América Latina, a bacia do Uruguai, parte da anterior, sobrepõe as estruturas organizativas brasileiras de Santa Catarina e Rio Grande do Sul, sem contar que, no caso dos projetos referentes às hidrelétricas de Garabi, Panambi e Roncador, todos no horizonte do governo brasileiro, há que se considerar a participação argentina, já que a bacia drena também parte do país vizinho, aumentando a sobreposição e a complexidade da questão hidrelétrica.

Embora se trate do mesmo espaço, é possível perceber que os recortes são distintos. O que muda do recorte territorial (Coredes e ADRs) em relação ao regional (bacias e sub-bacias hidrográficas) é que, apesar de ambas contarem com ações institucionais, a segunda é mais fluída, menos atrelada aos referenciais político-administrativos. Eis a riqueza e a complexidade do desenvolvimento regional.

O "desenvolvimento local" se aproxima conceitualmente do regional porque ambos compreendem "subespaços subordinados às mesmas leis gerais de evolução, onde o tempo empiricizado entra como condição de possibilidade e a entidade geográfica preexistente entra como condição de oportunidade" (SANTOS, 2004, p. 108). Ainda que se considere a distinção entre lugar e região menos relevante do ponto de vista hierárquico do espaço ao nível até de uma região poder ser considerada local e vice-versa (SANTOS, 2004), do ponto de vista do desenvolvimento, na perspectiva das hidrelétricas, alguma distinção parece ser importante. Ao falar em desenvolvimento local ou do local, faz-se referência a um ponto preciso da região ou território mais amplo em que este está inserido (BOISIER, 2000). No caso da instalação de uma hidrelétrica, por exemplo, tem-se a região em questão, a bacia do Uruguai ou o Alto Uruguai; depois, tem-se o local do empreendimento, que é o ponto onde os trabalhos de instalação acontecem, a dizer, o município, o distrito desse município ou a comunidade local. Um exemplo é o caso da instalação da UHE Itá, no rio Uruguai. 
Figura 1 - Região hidrográfica da bacia do Prata

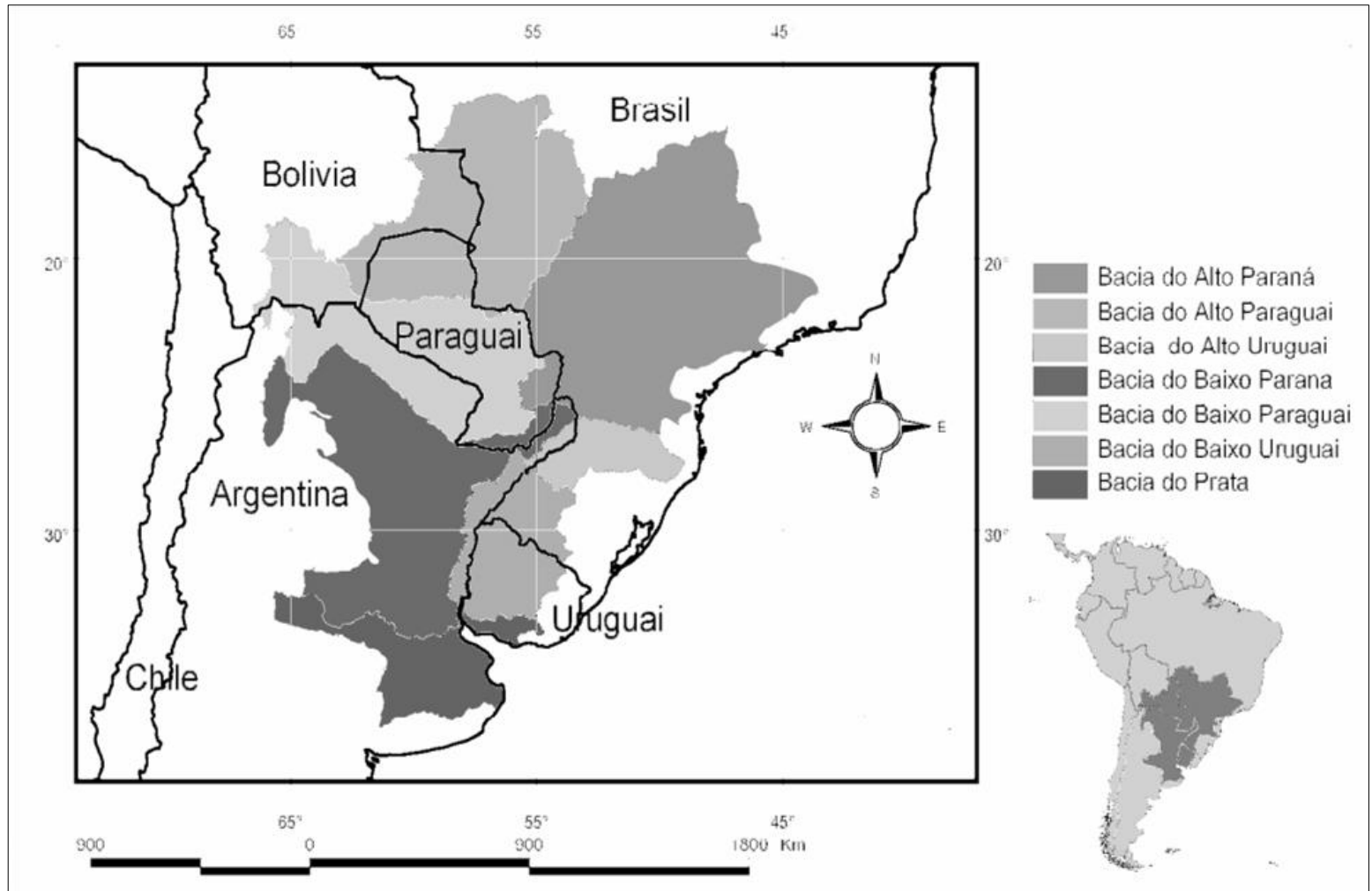

Fonte: Disponível em: <http://www.epe.gov.br>. Acesso em: 02 fev. 2019.

Figura 2 - Mapa da região da UHE Itá

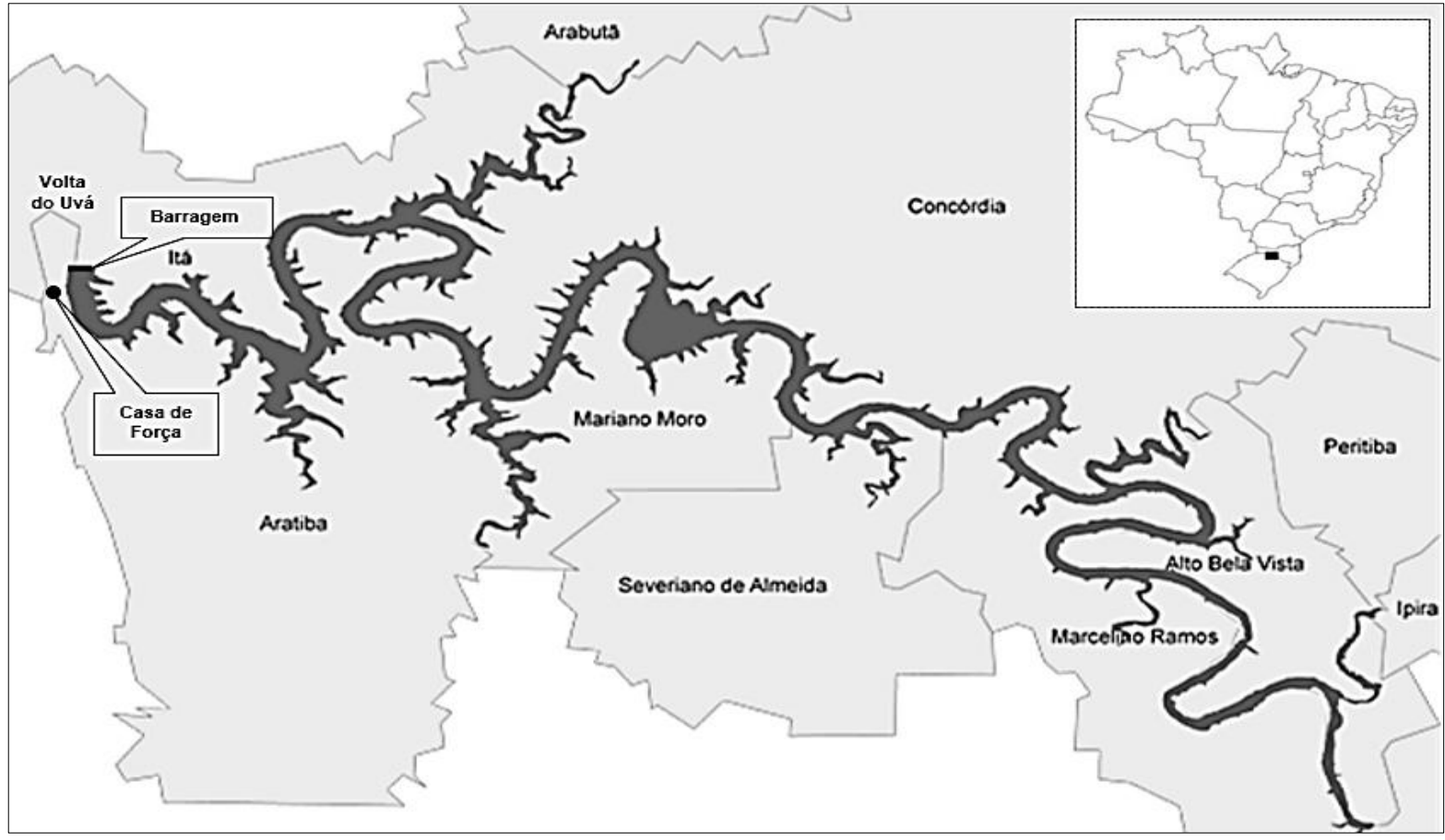

Fonte. Disponível em: <http://www2.aneel.gov.br/aplicacoes/cmpf/gerencial/>. Acesso em: 31 jan. 2018. (Adaptado pelo autor.)

Na Figura 2, pode-se perceber a sobreposição de todos os outros recortes apresentados até aqui. A diferença é que a região assume uma conotação ainda mais específica, e o desenvolvimento "local" vai se referir aos municípios que estão 
diretamente afetados pelo projeto de grande escala; no caso, a hidrelétrica. Isso implica que, enquanto o restante do país conta com a energia gerada pela hidrelétrica, o ônus socioambiental tende a ser dividido imediatamente entre as populações regionais, o que é provável que se agrave de acordo com a proximidade da obra propriamente dita, ou seja, do "local" do projeto.

A distinção entre desenvolvimento territorial, regional e local representa muito mais um recorte metodológico do que uma diferença que funcione de forma excludente. Então, metodologicamente, tem-se o conceito de "desenvolvimento regional" como aquele que mais bem aborda a complexidade da questão hidrelétrica, o que, em alguns momentos, precisa ser complementado com a ideia de "desenvolvimento local" para se referir ao epicentro do projeto de grande escala, ao passo que o desenvolvimento territorial servirá, neste caso, como pano de fundo para a discussão na perspectiva político-institucional.

\section{0 enclave como uma especificidade das hidrelétricas para o desenvolvimento regional}

Identificadas as noções genéricas que balizam as análises multiescalares do desenvolvimento, podemos apresentar uma proposta teórico-metodológica considerando os Projetos de Grande Escala (PGE). Para tal, conceituaremos a ideia de PGE enquanto "enclaves" para depois analisarmos as implicações dessa conceituação.

Gustavo Lins Ribeiro (1987) caracteriza os PGE, sobretudo, mediante três fatores relacionados: "gigantismo", “isolamento" e "temporariedade". O "gigantismo" inclui, para além da grandeza física, a enorme demanda de capital e trabalho envolvida. Por causa dessa dimensão, os PGE causam grandes mudanças locais que refletem regional, nacional e internacionalmente; todavia, essa alternância escalar é planejada a partir de uma estrutura centralizada de articulação das ações nas diferentes escalas (RIBEIRO, 1987). O "isolamento" se refere antes ao isolamento socioeconômico do que ao geográfico, por implicar a capacidade dos PGE de se inserirem em determinada região sem que esta tenha, obrigatoriamente, estruturas preexistentes que supram as necessidades de mão de obra e material para a sua execução (RIBEIRO, 1987). Já a "temporariedade" dos PGE os caracteriza como "sistemas fechados no tempo: começam e acabam num lapso relativamente curto" (RIBEIRO, 1987, p. 17).

$O$ gigantismo supõe que os PGE promovam naturalmente $O$ desenvolvimento dos locais onde venham a se inserir, especialmente na fase em que os trabalhos de instalação são mais agudos. $O$ isolamento faculta o que se considera uma zona de "enclave" na qual se constitui um território de "ambiguidade jurídica" onde os empreendedores desempenham papéis originalmente estatais. Nesse sentido, o Estado se ausenta em favor da "otimização" da produção (RIBEIRO, 1987). Nesse território controlado pelo PGE, impõe-se um controle do tempo que obedece ao ritmo dos trabalhos e aos custos do projeto (RIBEIRO, 1987).

Dentre os três elementos que compõem um PGE, sobressai para a discussão do desenvolvimento o conceito de "enclave" como referência para a análise do desenvolvimento regional. Vainer e Araújo (1992, p. 28) assinalam que, desde a 
década de 1970 no Brasil, "a totalidade do território não é vista nem como conjunto de regiões hierarquicamente articuladas, nem como amálgama de regiõesprograma, mas como um somatório de recursos mais ou menos acessíveis". Embora os autores utilizem a denominação "Grandes Projetos de Investimento" (GPI), suas ideias se aproximam das de Ribeiro (1987) quando afirmam que o Estado viabiliza a ação sobre os recursos dos territórios por meio de políticas setoriais (VAINER; ARAÚJO, 1992). Na mesma linha, Ribeiro (1987) aponta "o encontro de processos sociais exógenos e endógenos" como perspectiva analítica. Segundo o autor, os primeiros seriam mantidos por burocracias nacionais e internacionais planificadas e fortemente coercitivas, ao passo que os últimos se referem às realidades das populações locais envolvidas nesses projetos (RIBEIRO, 1987).

Revisitando o tema, Vainer (2007) reforça que os enclaves ainda preponderam; porém, atualmente "grande parte das empresas e de seus empreendimentos territoriais não estão mais sob o controle do Estado brasileiro", como acontecia na década de 1970, mas são concebidos a partir de "grupos de interesses e lobbies, coalizões políticas que expressam, quase sem mediações, articulações econômico-financeiras e políticas", segundo as quais o "local, o regional, o nacional e o global se entrelaçam e convergem na constituição de consórcios empresariais e coalizões políticas" (VAINER, 2007, p. 12). Dessa forma, os PGE representam o agrupamento de interesses multiescalares que se organizam para inserir seus empreendimentos em determinados locais. Essa inserção promotora de uma verdadeira "integração desintegradora" (ROCHA, 2012) reconfigura o espaço através da hegemonização de uma temporalidade no respectivo território por meio de estratégias de "controle do espaço-tempo" (ROCHA, 2014), de maneira que as noções de espaço, território, territorialidade, tempo e temporalidade são sobrepostas pelos enclaves.

Quando um PGE é proposto para uma região, um processo de licenciamento ambiental é iniciado. Todavia, o que seria para garantir a sustentabilidade do desenvolvimento para a região acaba se tornando um mecanismo de consolidação do enclave. $O$ Artigo $1^{\circ}$ da Resolução n. 001 do Conselho Nacional do Meio Ambiente (CONAMA), de 23 de janeiro de 1986, prevê que seja considerado "impacto ambiental"

qualquer alteração das propriedades físicas, químicas e biológicas do meio ambiente, causada por qualquer forma de matéria ou energia resultante das atividades humanas que, direta ou indiretamente, afetam: I - a saúde, a segurança e o bem-estar da população; II - as atividades sociais e econômicas; III - a biota; IV - as condições estéticas e sanitárias do meio ambiente; $\mathrm{V}$ - a qualidade dos recursos ambientais.

Tendo em vista que os PGE tendem a provocar tal impacto, são obrigatórios o Estudo de Impacto Ambiental (EIA) e consequentemente o Relatório de Impacto Ambiental (RIMA) para a inserção desses PGE nas respectivas regiões. Dentre as finalidades do EIA, cabe destacar dois itens do Artigo $5^{\circ}$ da mesma Resolução:

III - Definir os limites da área geográfica a ser direta ou indiretamente afetada pelos impactos, denominada área de influência do projeto, considerando, em todos os casos, a bacia hidrográfica na qual se localiza; IV - Considerar os planos e programas governamentais, propostos e em implantação na área de influência do projeto, e sua compatibilidade. 
Parágrafo Único - Ao determinar a execução do estudo de impacto ambiental o órgão estadual competente, ou o IBAMA ou, quando couber, o Município, fixará as diretrizes adicionais que, pelas peculiaridades do projeto e características ambientais da área, forem julgadas necessárias, inclusive os prazos para conclusão e análise dos estudos.

Então, através do EIA-RIMA, determina-se um novo território dentro de um já existente, onde serão desenvolvidas políticas públicas específicas. Já quanto ao método a ser utilizado para a definição dessa área, a referida Resolução, em seu Artigo $6^{\circ}$, inciso I, prevê que devem ser considerados os meios "físico", "biológico e os ecossistemas naturais" e "socioeconômico". A determinação da magnitude dos impactos e, como resultado, da área de abrangência do PGE será feita, ainda segundo os artigos $7^{\circ}$ e $8^{\circ}$ da Resolução n. ${ }^{\circ}$ 001/86 do CONAMA, por uma equipe multidisciplinar custeada pelos empreendedores.

Com base nessa prerrogativa, essas equipes multidisciplinares especificam os conceitos de Impacto Ambiental Regional e Áreas de Influência Direta e Indireta. A Resolução n. ${ }^{\circ} 237$ do CONAMA, de 19 de dezembro de 1997, em seu Artigo ${ }^{\circ}$, inciso IV, define "Impacto Ambiental Regional" como sendo "todo e qualquer impacto ambiental que afete diretamente (área de influência direta do projeto), no todo ou em parte, o território de dois ou mais Estados". Por sua vez, o Anexo I da Resolução n. 305 do CONAMA, de 12 de junho de 2002, define "Área de influência direta" como sendo aquela

necessária à implantação de obras/atividades, bem como aquelas que envolvem a infraestrutura de operacionalização de testes, plantios, armazenamento, transporte, distribuição de produtos/insumos/água, além da área de administração, residência dos envolvidos no projeto e entorno.

Já a "Área de influência indireta" compreende o "conjunto ou parte dos municípios envolvidos, tendo-se como base a bacia hidrográfica abrangida".

Estabelecido esse polígono do empreendimento, o enclave acontece por meio de Declaração de Utilidade Pública, a qual, prevista no inciso XXIV do Artigo $5^{\circ}$ da Constituição Federal, ampara legalmente a apropriação do território pelos empreendedores mediante indenização das populações locais. Dessa forma, a reconfiguração do espaço por meio do enclave está efetivada, suplantando, do ponto de vista das políticas públicas, as noções iniciais de território, região e local para efeito de análise do desenvolvimento. Sobre isso, são importantes algumas ressalvas sobre o modo como essa reconfiguração ocorre.

Em 2007, o Ministério Público Federal (MPF), a partir de um corpo técnico multidisciplinar, emitiu uma Nota Técnica baseada na análise de 89 Informações Técnicas referentes a empreendimentos instalados no Brasil entre os anos de 1997 e 2005, dentre os quais estão incluídas hidrelétricas (MPF, 2007). No que tange aos "recortes espaciais", a equipe do MPF concluiu que, considerando as delimitações segundo "bacia hidrográfica", "divisão geopolítica" e "área do empreendimento e seu entorno", embora a normativa do CONAMA aponte a primeira, as duas últimas delimitações predominam nos empreendimentos analisados (MPF, 2007). Aprofundando os pontos mais sensíveis, a equipe assinalou: 
e) insuficiência dos limites da área de influência, tendo em vista o ElA ter considerado apenas o espaço de ação e as instalações do empreendimento;

f) uso de limites arbitrários e rígidos, sem justificativa técnica, tais como divisões geopolíticas ou linhas imaginárias traçadas a certa distância (raio de alguns quilômetros) de um ponto selecionado, não permitindo considerar a homogeneidade de fatores importantes, tais como o contexto geológico e geomorfológico, além das bacias e sub-bacias hidrográficas; e

g) delimitação de áreas de influência estanques para os meios físico, biótico e antrópico, desconsiderando a unidade do meio ambiente e prejudicando a análise integrada e global dos impactos, não permitindo sua adequada avaliação (MPF, 2007, p. 27).

Na mesma linha, Fonseca e Bitar (2012) analisaram o conteúdo de Termos de Referência (TRs) e de EIA-RIMAs de diferentes PGE no Brasil, além de ouvir a opinião dos profissionais envolvidos na elaboração desses documentos. Dentre os pontos levantados pelos autores, destaca-se o fato de que "o modo pelo qual são construídos os TRs atualmente, a equipe técnica que elabora o EIA-RIMA acaba sendo levada a estabelecer, ela própria, os critérios para a delimitação das áreas de influência" (FONSECA; BITAR, 2012, p. 9). Isso é acrescido pelo registro dos próprios técnicos, que reclamam do pouco tempo que dispõem para realizar os estudos e da falta de uma padronização da metodologia empregada (FONSECA; BITAR, 2012). Quanto à delimitação da área de abrangência dos PGE, os autores indicam a necessidade de

\begin{abstract}
padronização de nomenclaturas das áreas de influência utilizadas nos estudos; definição de critérios mínimos para o estabelecimento da área de influência; [...] conceituação e distinção claras entre área de influência de impacto ambiental e área do diagnóstico ambiental; e estabelecimento de condicionantes para a revisão da área de influência dos impactos durante a elaboração do EIA/Rima, bem como na instalação e operação do empreendimento (FONSECA; BITAR, 2012, p. 13-14).
\end{abstract}

Ambas as pesquisas apontaram fatores que atestam a insuficiência da atual metodologia de delimitação das áreas de influência dos Projetos de Grande Escala (PGE). Falta de padronização nos conceitos, pouco tempo de discussão e delimitações arbitrárias são pontos que aparecem em diferentes momentos das avaliações sobre os empreendimentos. Mas o que chama a atenção, sob o ponto de vista do desenvolvimento, a partir desses PGE, é o que ambas as pesquisas enfatizaram como ponto primordial para o avanço no debate: "a participação pública" nos processos decisórios - sobre o que ambos reiteram o caráter incipiente (MPF, 2007; FONSECA; BITAR, 2012). Esses aspectos fecham esta seção, deixando claro que a promoção do desenvolvimento com os PGE merece ser analisada retomando as noções políticas apresentadas ao longo do texto, sob pena de considerar o crescimento econômico por si como algo natural em função do gigantismo desses projetos. 


\section{Um exercício mínimo de análise: o caso da UHE Itá}

Tomando como exemplo o caso da UHE Itá, teremos a bacia hidrográfica do Uruguai, o Alto Uruguai ou o conjunto de municípios atingidos como referencial regional, ao passo que, como referencial de local, estarão os municípios de AratibaRS e Itá-SC, ponto do rio em que está localizado o eixo da usina (especialmente a casa de força) e onde se concentram os trabalhos de instalação e operação da hidrelétrica. Embora tenha sido originalmente concebida em esfera estatal, a UHE Itá começou a ser construída efetivamente em 1996 a partir de uma parceria entre Estado e empresas privadas. Situada no rio Uruguai entre os municípios de AratibaRS e Itá-SC, a hidrelétrica tem potência de $1.450 \mathrm{MW}$ a partir de uma barragem de 880 metros de comprimento e 375,5 metros de altura, o que se reflete em um reservatório com área total de $141 \mathrm{~km}^{2}$ (ENGIE, 2018). Esse reservatório atingiu 4.704 famílias (NUTI, 2007) em 10 municípios da região, sendo: Aratiba, Marcelino Ramos, Mariano Moro e Severiano de Almeida, no Rio Grande do Sul, e Alto Bela Vista, Arabutã, Concórdia, Ipira, Itá e Peritiba, em Santa Catarina.

Desde a publicação do plano de exploração hidrelétrica, a região passou a alternar sentimentos de incerteza e expectativa. No que se refere ao aspecto econômico, o propositor da obra já projetava no ano de 2000 que

além dos royalties e do maior retorno de ICMS, os 11 municípios que margeiam o lago terão uma grande possibilidade de exploração turística. Afinal, o lago é propício à navegação, esportes náuticos, pesca e várias outras atividades. A própria usina é um centro de convergência de interesses, assim como a arquitetura da nova cidade de Itá (CONSÓRCIO ITÁ, 2000, p. 146).

A perspectiva de Compensação Financeira pela Utilização de Recursos Hídricos (CFURH) ${ }^{3}$, comumente chamada de - e confundida com - royalties, é recorrente quando da implantação desses Projetos de Grande Escala. Todavia, em estudo feito no município de Mondaí-SC, o qual está ameaçado pela possibilidade de instalação da UHE Itapiranga, Baron et al. (2010) concluem que a diferença entre a receita oriunda da CFURH e as perdas com área e população seria na ordem de 1 para 6. A constatação dos autores suscita a importância de uma análise mais cuidadosa sobre a chance efetiva de "compensação" desse mecanismo. Analisando os dados disponibilizados pelo IBGE (2017) e pela ANEEL (2017) acerca da UHE Itá, percebe-se que, apenas nos municípios de Mariano Moro-RS (4,95\%) e Alto Bela Vista-SC (3,81\%), a CFURH apresenta algum destaque no PIB; nos demais municípios atingidos, com exceção de Marcelino Ramos-RS (1,46\%), a CFURH não chega a $1 \%$ da totalidade produzida. A participação mais expressiva da CFURH nos municípios de Mariano Moro-RS e Alto Bela Vista-SC se explica por esses municípios terem sido os mais atingidos, sendo que o primeiro perdeu $16,50 \%$, e o segundo, $15,26 \%$ da sua área alagada pelo lago da UHE Itá. Isso, relacionado ao baixo PIB, representa um peso maior da CFURH em vista de que essas perdas incidiram diretamente sobre a

\footnotetext{
${ }^{3}$ A CFURH é uma compensação financeira paga ao município pelo propositor da hidrelétrica em função da área alagada pela usina, regulamentada pela Lei n. ${ }^{\circ}$ 7.990, de 28 de dezembro de 1989.
} 
principal fonte de recursos, que é a agricultura familiar; logo, perda de área e população têm um impacto maior no PIB.

O aquecimento econômico que um Projeto de Grande Escala (PGE) pode representar para uma região em função da oferta de empregos e demanda por serviços costuma também servir como propaganda quando da inserção dessas obras nas regióes no sentido do crescimento econômico que podem fomentar, conforme apresentado na citação do empreendedor na seção anterior deste trabalho. Para tentar perceber indícios desse crescimento, é interessante o gráfico abaixo (Figura 3) sobre a evolução do PIB dos municípios atingidos. Serão tomados como parâmetros os anos de 1980, quando se começou a discutir a instalação da usina; o ano de 2000, quando da sua entrada em operação; e o ano de 2015, para mostrar a evolução posterior, quando a concessão atinge a "meia vida", por as concessões das hidrelétricas normalmente serem feitas para 30 anos renováveis.

Figura 3 - Evolução do PIB nos municípios atingidos pela UHE Itá

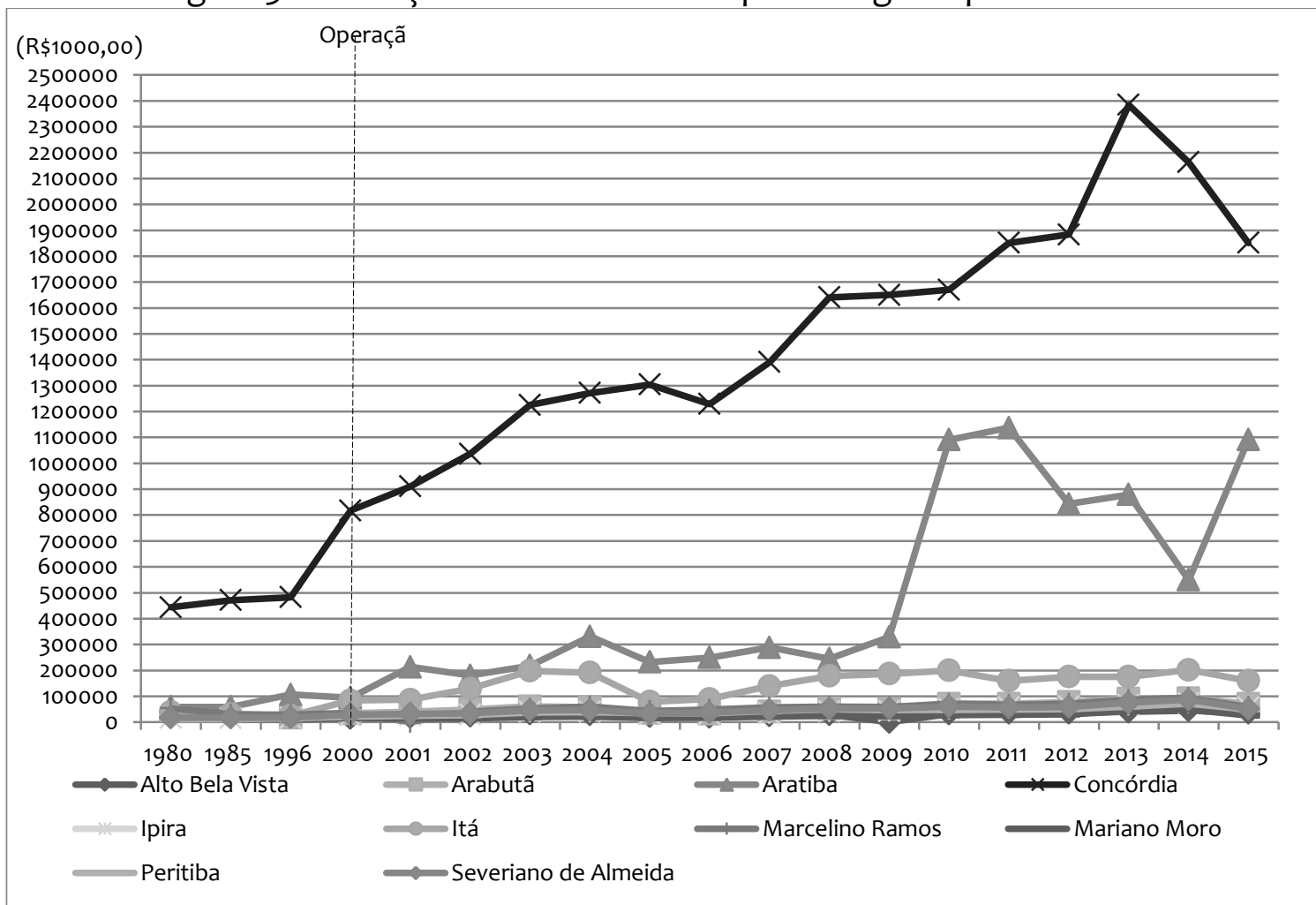

Fonte: Elaborado pelo autor com base em dados do IPEA (2017) e do IBGE (2017).

Os dados sobre o PIB regional demonstram o distanciamento entre Concórdia-SC e os demais municípios; todavia, destacam-se os municípios de Aratiba-RS e Itá-SC. Quanto aos demais municípios atingidos, percebe-se a estabilidade em relação ao período anterior à hidrelétrica. Ainda sobre ConcórdiaSC, nota-se que o PIB do município demonstra crescimento anterior ao período da hidrelétrica, o que reforça a ideia de que o crescimento econômico do município não passa necessariamente pela hidrelétrica, mas pela notória atividade agroindustrial.

Sobre a incidência da CFURH sobre o desenvolvimento regional, são importantes dois pontos apresentados por Gomes (2014) em sua pesquisa sobre o 
Alto Uruguai, em que mostra que os municípios que recebem CFURH têm desenvolvimento mais lento em relação àqueles que não são atingidos e não recebem a mesma compensação. A explicação pode ser que, embora os não atingidos não recebam o recurso, mantiveram área e população, o que é ponto importante em uma economia baseada na agricultura familiar. Depois, o fato de a CFURH não ter nenhuma vinculação para aplicação, somado à falta de planejamento, podem ser outras causas da inércia desse recurso no desenvolvimento regional (GOMES, 2014).

O município de Itá-SC acompanha o desempenho médio dos municípios da região até o início dos trabalhos de instalação da hidrelétrica em 1996, a partir do que o município passa a exibir melhora no PIB em função do mencionado aquecimento econômico. Mas apenas os empregos e o aquecimento econômico não seriam suficientes para representar um aumento consolidado no desempenho do município, uma vez que esses Projetos de Grande Escala correspondem a eventos temporários que implicam concomitantemente sobrecarga da estrutura municipal devido ao aumento repentino de pessoas.

Outro elemento a ressaltar é o bom desempenho do município de AratibaRS, que também sedia a usina, só que do lado gaúcho do rio Uruguai. A explicação desse desempenho está no modelo atual de tributação sobre a geração de energia elétrica. Não obstante a tributação aconteça em escala federal, estadual e municipal, a tributação referente ao Imposto sobre Operações relativas à Circulação de Mercadorias e sobre Prestações de Serviços de Transporte Interestadual e Intermunicipal e de Comunicação $(I C M S)^{4}$ incide mais diretamente sobre a economia e o desenvolvimento dos municípios.

Os Índices de Participação Municipal (IPM) - disponibilizados pela Frente Nacional de Prefeitos (FNP) (2018) e pelo CONFAZ (2018) e correspondentes às porcentagens a que têm direito os respectivos municípios em relação ao ICMS arrecadado pelas respectivas Unidades da Federação (neste caso, Santa Catarina e Rio Grande do Sul) - permitem perceber que o município de Concórdia-SC tem o maior IPM entre os municípios atingidos, mantendo uma média de 1,202\% ao longo da série histórica abrangida. Há que se reiterar que esse desempenho já é registrado antes da instalação da UHE Itá e, consequentemente, dos repasses de CFURH. Em segundo lugar, está o município de Itá-SC, com índice médio de 0,720\% no período observado. O desempenho do município de Itá-SC tem relação direta com a (re)construção do núcleo urbano. O importante nisso é que a construção de uma cidade inteira repercute na movimentação de serviços, alterando drasticamente o

\footnotetext{
${ }^{4}$ Instituído pela Constituição Federal de 1988 (inciso II do Artigo 155) e regulamentado pela Lei Complementar n. ${ }^{\circ}$ 87, de 13 de setembro de 1996 (Lei Kandir), a cobrança e repasse do ICMS é competência das respectivas Unidades da Federação. O "fato gerador" do ICMS, ou seja, aquilo que autoriza a sua cobrança, acontece quando da saída de uma mercadoria do fornecedor, o qual, em tese, emite uma nota fiscal sobre a qual incidirá o ICMS, que deverá ser pago pelo destinatário desta. Esse ICMS fica $75 \%$ com a própria Unidade da Federação e os outros $25 \%$ são repassados para o Município onde o "fato gerador" aconteceu, ou seja, a geração da energia. No caso da UHE Itá, o ICMS é recolhido pelo Estado do Rio Grande do Sul e repassado ao município de Aratiba, local onde está sediada a "casa de força" - tecnicamente, o local onde a energia (mercadoria) é gerada (produzida e vendida).
} 
ICMS. Ademais, se verificado o ICMS do município, a maior parte vem da indústria, a qual tem na hidrelétrica sua origem principal.

O município de Aratiba-RS, outro destaque, com um percentual de 0,414\%, também tem na indústria a sua principal fonte de ICMS. Ocorre que, sendo AratibaRS um município essencialmente agrícola, a chegada da UHE Itá incidiu de modo decisivo no aumento da arrecadação. Aqui se pode perceber o caso explícito em que a hidrelétrica promove o "desenvolvimento local”, sobretudo por conta do retorno do ICMS. Isso porque é em Aratiba que ocorre o "fato gerador", por sediar a casa de força da hidrelétrica, local onde, tecnicamente, se produz a energia considerada mercadoria -; logo, arrecada-se o ICMS.

A evolução da arrecadação de ICMS corrobora a arrecadação superior do município de Concórdia-SC, seguida por Aratiba-RS e Itá-SC. Os demais municípios apresentam crescimento que acompanha as médias estaduais, sem que se perceba um salto parecido aos casos dos municípios que estão no eixo da hidrelétrica. Assim, pode-se afirmar que, em termos de crescimento econômico, a UHE Itá impulsionou os municípios em que o ICMS é arrecadado ao mesmo tempo que, nos demais municípios, os quais contam apenas com a CFURH, não se nota crescimento em função da chegada da hidrelétrica. Apesar disso, há que se registrar que, segundo Gomes (2014), enquanto os municípios recebedores do ICMS tiveram maior crescimento econômico, a desigualdade de renda também aumentou nesses locais em comparação com a região. Ainda conforme a autora, isso pode estar atrelado ao fato de se tratar de um modelo de desenvolvimento exógeno que encontra explicação na ideia de "enclave" como ponto crucial de dificuldade do desenvolvimento regional.

Conhecidos os números gerais acerca do crescimento econômico, pode-se partir então para a análise do "desenvolvimento", o que será discutido com base no Índice de Desenvolvimento Humano (IDH) dos municípios atingidos em relação aos respectivos Estados e país. De acordo com o PNUD (2018), o IDH do Estado de Santa Catarina sempre esteve ligeiramente acima do IDH do Rio Grande do Sul, sendo que essa diferença aumenta geometricamente em cada parcial (1 ponto em 1991; 10 pontos em 2000; 28 pontos em 2010). No tocante ao Brasil, historicamente os dois Estados apresentam índices superiores, embora a média brasileira venha se aproximando da média do Rio Grande do Sul. Assim, além dos parâmetros institucionais, a média catarinense serve como linha superior; o índice gaúcho, como referência intermediária; e o índice nacional, como parâmetro de referência inferior.

O gráfico abaixo (Figura 4) mostra o IDH dos municípios atingidos na série histórica, considerando três datas de referência: o ano de 1991, antes da hidrelétrica, período em que ainda não eram computados os recursos de CFURH e ICMS; o ano de 2000, quando esses recursos passaram a compor as receitas dos municípios em razão da entrada em operação; e dez anos depois (2010), o que permite a perspectiva da incidência desses recursos sobre o desenvolvimento regional. 
Figura 4. Evolução do IDH dos municípios atingidos pela UHE Itá

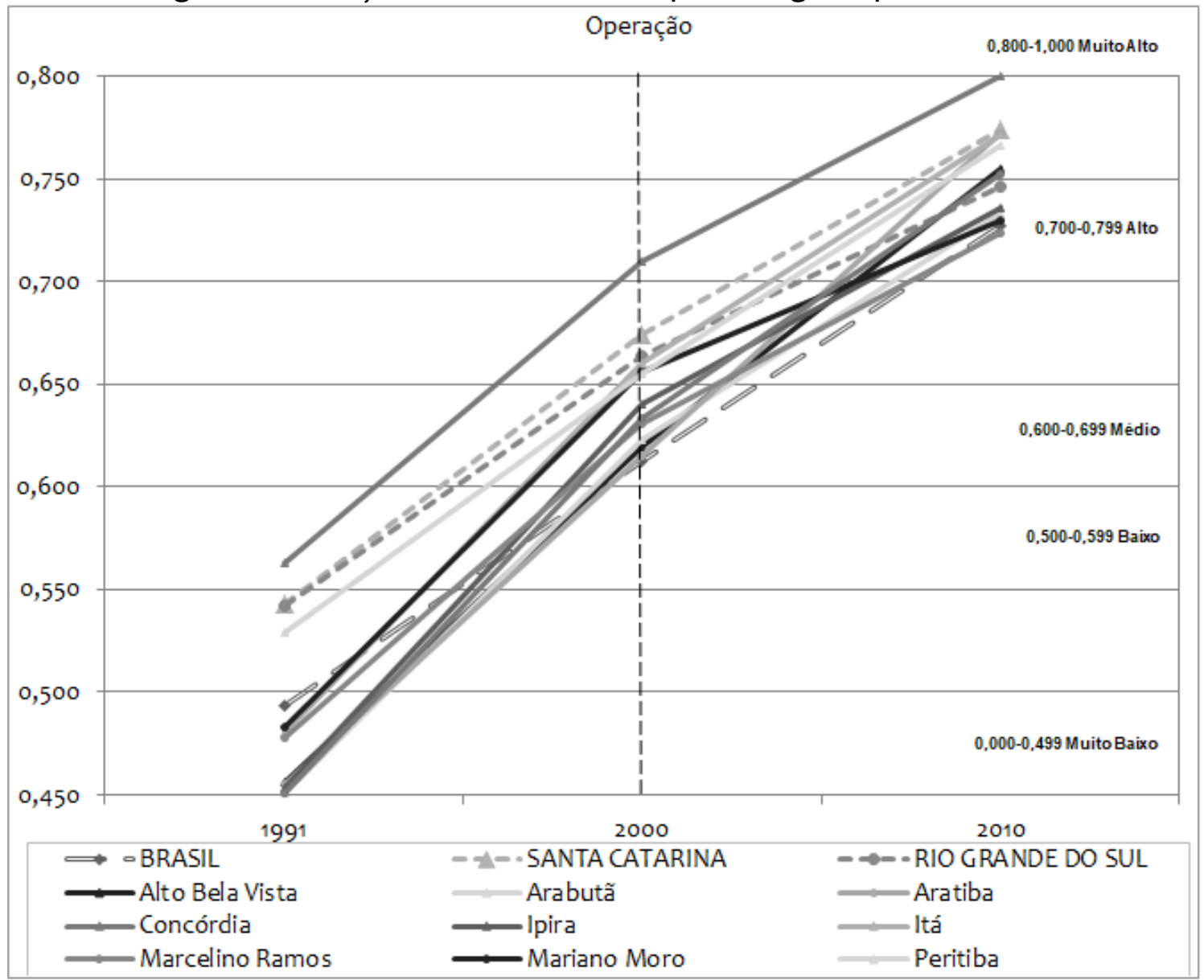

Fonte: Elaborado pelo autor a partir de dados do PNUD (2017).

Em 1991, o IDH dos municípios atingidos pela UHE Itá era considerado Baixo (Concórdia-SC e Peritiba-SC) ou Muito Baixo (Alto Bela Vista-SC, Arabutã-SC, IpiraSC, Itá-SC, Aratiba-RS, Marcelino Ramos-RS, Mariano Moro-RS e Severiano de Almeida-RS). O índice dos Estados era considerado Médio, ao passo que o Brasil apresentava um desempenho considerado Muito Baixo. Fazendo a comparação na região, antes da chegada da hidrelétrica, apenas Concórdia-SC estava acima da média nacional e dos Estados de Santa Catarina e Rio Grande do Sul. Todos os outros municípios estavam abaixo das médias dos seus Estados, sendo que apenas Peritiba-SC estava acima da média nacional.

Em 2000, considerando os parâmetros do PNUD, todos os municípios tiveram melhora, atingindo o conceito Médio. Concórdia-SC se manteve acima dos índices estaduais e nacional e atingiu o nível Alto estabelecido pelo PNUD. Comparando os dados entre si, todos os municípios superaram a média nacional. Embora a região tenha mostrado um aumento abrupto dos índices, continuou abaixo das médias estaduais. A exceção é Itá-SC, que praticamente se igualou ao índice do Rio Grande do Sul, o qual tomamos aqui como uma linha média intermediária de desenvolvimento; a cidade teve a maior evolução dentre todos os municípios (subiu 180 pontos), o que está relacionado com a reconstrução da cidade entre os anos de 1984 e 1994. 
Em 2010, todos os municípios seguiram em ascensão, atingindo o nível Alto estabelecido pelo PNUD. O município de Concórdia-SC continuou acima de todos os índices, chegando à classificação de IDH Muito Alto. O destaque inferior é o município de Marcelino Ramos-RS, único que ainda não superou a média nacional. Os municípios de Arabutã-SC, Ipira-SC e Mariano Moro-RS superaram a média nacional, mas continuaram abaixo da média gaúcha (linha intermediária). Os municípios de Alto Bela Vista-SC, Peritiba-SC, Severiano de Almeida-RS, Aratiba-RS e Itá-SC superaram os índices do Rio Grande do Sul. Aqui, novamente Itá-SC e AratibaRS (município que mais aumentos o IDH, 157 pontos) se destacaram, encostando na média catarinense, considerada a melhor referencial regional, o que ratifica a ideia do desenvolvimento local em detrimento ao regional.

De maneira geral, pode-se constatar que os municípios da região ascenderam, acompanhando a evolução nacional e dos Estados se considerarmos os parâmetros estabelecidos pelo PNUD. A média nacional foi superada, e os municípios projetam melhoras em relação ao Rio Grande do Sul e se aproximam das médias de Santa Catarina. Seguindo na perspectiva do trabalho, o desenvolvimento diferenciado dos municípios de Itá-SC e especialmente o de Aratiba-RS (município que mais aumentou seu índice na série histórica, 317 pontos) sugere a localização do desenvolvimento em contraponto ao esperado desenvolvimento regional fomentado pela chegada da hidrelétrica.

\section{Considerações finais: relativizando com elementos qualitativos}

A complexidade inerente à hidreletricidade, sobretudo enquanto promotora do desenvolvimento regional, precisa ser feita relacionando elementos econômicos, ambientais e políticos. Embora se tome o caso da UHE Itá para discussão neste trabalho, o replique da metodologia indica a recorrência dos resultados nas outras UHE da bacia hidrográfica, mas falta espaço neste trabalho para uma discussão abrangente. Partindo dos dados quantitativos, percebe-se que o crescimento econômico dos municípios a partir da instalação da hidrelétrica é praticamente irrisório. Quanto ao IDH, nota-se um aumento no índice em todos os municípios; todavia, é preciso considerar que essa evolução acompanha uma tendência verificada também nos municípios que não contam com hidrelétricas em seus territórios.

Merecem considerações mais específicas as performances dos municípios de Concórdia e Itá, em Santa Catarina, e Aratiba, no Rio Grande do Sul. Concórdia representa um ponto fora da curva desde antes da chegada da hidrelétrica, o que se justifica pela notória tradição agroindustrial do município, sendo que a participação da hidrelétrica no PIB municipal é pouco expressiva. Itá recebeu incremento no PIB por ter seu núcleo urbano transferido em função do alagamento, o que se reflete em um aquecimento econômico, mesmo que temporário. Aratiba pode ser considerado o município em que o PIB realmente é incrementado com relação direta com a hidrelétrica. Entretanto, da mesma forma que isso não se mostra retratado nitidamente no IDH, esse crescimento não se reproduz regionalmente. Isso ocorre devido ao modo de distribuição das compensações vigente no país. Ainda sobre esse ponto, é importante registrar a guerra fiscal estabelecida entre os 
municípios de Itá e Aratiba por ocasião desses recursos, ainda que falte espalho neste trabalho para aprofundamento.

A pouca relação entre o desenvolvimento regional e a hidrelétrica pode ser compreendida se retomado o processo de instalação. A concepção do projeto se deu em uma escala global, e a inserção no local pode ser contestada no que diz respeito à participação da comunidade. A densidade institucional revela a predominância de grupos exógenos (governo, empresas) em detrimento à comunidade atingida. A cadeia de valor se estabelece a partir de insumos e técnicas também exógenas, as quais pouco ou nada inovam regionalmente.

O processo de instalação instituiu um conflito entre empreendedores e a comunidade local de forma que os resultados positivos do ponto de vista material, em certa medida, correspondem a ações de pressão popular, conforme demonstram inúmeras pesquisas, dentre as quais destacamos os trabalhos de Rothman (1996) e Reis (1998). Nesse ponto, mesmo que traumático, o processo resultou no empoderamento da população local; no entanto, revela-se ao longo do tempo a debilidade democrática e o baixo índice de capital social, o que se define a partir do momento em que o projeto é concebido alheiamente à vontade regional, pelo menos daqueles que serão diretamente atingidos. Configurado o projeto globalmente, a inserção mediante enclave assevera as limitações políticas e restringe as possibilidades de incremento da economia regional, visto que o gigantismo e o isolamento desses projetos de grande escala permitem apenas uma participação coadjuvante das populações locais, a qual, quando ocorre, é efêmera.

A partir do que foi apresentado neste trabalho, constata-se que, em função do modo como as hidrelétricas são concebidas globalmente e inseridas enquanto Projetos de Grande Escala nos locais, estabelecendo um enclave praticamente alheio à vontade regional, são poucas as chances de esse projeto significar alguma inovação que promova o desenvolvimento regional. Depois, mesmo que as hidrelétricas tenham potencial de incremento, não só da arrecadação mediante tributos e compensações, a forma como tal metodologia se mostra atualmente diminui as chances de desenvolvimento regional, limitando-se apenas à possibilidade de desenvolvimento local, o que também precisa ser considerado no caso concreto devido à desobrigação de destinação do recurso e à insuficiência de planejamento, o que se reflete no aumento da desigualdade social.

\section{REFERÊNCIAS}

AGÊNCIA NACIONAL DE ENERGIA ELÉTRICA (ANEEL). Compensação financeira pela utilização de recursos hídricos: relação de estados beneficiários: planilha dos municípios totalização anual. Disponível em:

http://www2.aneel.gov.br/aplicacoes/cmpf/gerencial/ Acesso em: 19 dez. 2017.

\section{AGÊNCIA NACIONAL DE ENERGIA ELÉTRICA (ANEEL). Histórico de geração da UHE}

Itá. Disponível em: <http://www2.aneel.gov.br/aplicacoes/cmpf/gerencial/>. Acesso em: 12 jan. 2018. 
BAQUERO, R. V. A. Empoderamento: instrumento de emancipação social?: uma discussão conceitual. Revista Debates, Porto Alegre, v. 6, n. 1, p. 173-187, jan./abr. 2012.

BARON, S. et al. Compensação financeira x produção agrícola renunciada: comparação entre compensação financeira da UHE Itapiranga para o município de Mondaí (SC) e a produção agrícola renunciada pela formação do reservatório da UHE. In: ENCONTRO LATINOAMERICANO DE CIÊNCIAS SOCIAIS E BARRAGENS, 3., 2010, Belém. Anais... Belém: Data Memory - LMR Alencar Ltda., 2010. v. 1, p. 2-28.

BECK, U. A reinvenção da política: rumo a uma teoria da modernização reflexiva. In: GIDDENS, A.; LASH, S.; BECK, U. Modernização reflexiva: política, tradição e estética na ordem social moderna. São Paulo: Editora da Unesp, 2012. p. 11-87.

BECKER, D. F. A contradição em processo: o local e o global na dinâmica do desenvolvimento regional. In: BECKER, D. F.; WITTMANN, M. L. Desenvolvimento regional: abordagens interdisciplinares. 2. ed. Santa Cruz do Sul: EDUNISC, 2008a. p. $67-115$.

BECKER, D. F. A economia política do (des)envolvimento regional contemporâneo. In: BECKER, D. F.; WITTMANN, M. L. Desenvolvimento regional: abordagens interdisciplinares. 2. ed. Santa Cruz do Sul: EDUNISC, 2008b. p. 37-66.

BOBBIO, N. O futuro da democracia: uma defesa das regras do jogo. 9. ed. Rio de Janeiro: Paz e Terra, 2000.

BOISIER, S. Desarrollo (local): ¿De qué estamos hablando? In: BECKER, D. F.; BANDEIRA, P. S. (Orgs.). Desenvolvimento local-regional: determinantes e desafios contemporâneos. Santa Cruz do Sul: EDUNISC, 2000. p. 151-185.

BRASIL. Constituição da República Federativa do Brasil: texto constitucional promulgado em 5 de outubro de 1988. Brasília: Senado Federal, 2009.

BRASIL. Lei n. ${ }^{\circ}$ 7.990, de 28 de dezembro de 1989. Diário Oficial, Brasília, DF, 29 dez. 1989.

BRASIL. Lei Complementar n. 87, de 13 de setembro de 1996. Diário Oficial, Brasília, DF, 16 set. 1996.

CHRISTOFOLETTI, A. Análise de Sistemas em Geografia. São Paulo: HUCITEC: EDUSP, 1979.

COMTE-SPONVILLE, A. O ser-tempo: algumas reflexões sobre o tempo da consciência. São Paulo: Martins Fontes, 2006.

CONSELHO NACIONAL DE POLÍTICA FAZENDÁRIA (CONFAZ). Boletim de arrecadação de ICMS disponível de dezembro de 1996 até a presente data. 
Disponível em: <https://www.confaz.fazenda.gov.br/legislacao/boletim-do-icms>. Acesso em: 29 jan. 2018.

CONSELHO NACIONAL DO MEIO AMBIENTE (CONAMA). Resolução n. ${ }^{\circ} 001$, de 23 de janeiro de 1986. Diário Oficial da União, Brasília, DF, 17 fev. 1986.

CONSELHO NACIONAL DO MEIO AMBIENTE (CONAMA). Resolução n. ${ }^{\circ} 237$, de 19 de dezembro de 1997. Diário Oficial da União, Brasília, DF, 22 dez. 1997.

CONSELHO NACIONAL DO MEIO AMBIENTE (CONAMA). Resolução n. ${ }^{\circ}$ 305, de 12 de junho de 2002. Diário Oficial da União, Brasília, DF, 4 jul. 2002.

CONSÓRCIO ITÁ. Memória de uma usina. Itá-SC: Consórcio Itá, 2000. Disponível em: www.consorcioita.com.br/fmanager/consorcioita/livro/arquivo1_1.pdf Acesso em: 23 jan. 2018.

ENGIE. Ficha Técnica UHE Itá. Disponível em:

http://www.tractebelenergia.com.br/wps/portal/internet/parque-gerador/usinashidreletricas/uhe-ita Acesso em: 23 jan. 2018.

FERNÁNDEZ, V. R. Densidad institucional, innovación colectiva y desarrollo de las cadenas de valor local: un triángulo estratégico en la evolución de los enfoques regionalistas durante los 90s. Redes, Santa Cruz do Sul, v. 9, n. 1., p. 735, jan./abr. 2004.

FRENTE NACIONAL DE PREFEITOS (FNP). IPM no ICMS em SC. Disponível em: http://comparabrasil.com/municipios/paginas/modulo8.aspx Acesso em: 10 jan. 2018.

FONSECA, W.; BITAR, O. Y. Critérios para delimitação de áreas de influência em estudos de impacto ambiental. In: CONGRESSO BRASILEIRO DE AVALIAÇÃO DE IMPACTO AMBIENTAL, 1; CONFERÊNCIA DA REDE DA LÍNGUA PORTUGUESA DA AVALIAÇÃO DE IMPACTOS, 2, 2012, São Paulo. Anais... São Paulo: ABAI, 2012. p. 0114.

FURTADO, C. O mito do desenvolvimento econômico. São Paulo: Círculo do Livro, 1974 .

GOHN, M. G. Empoderamento e participação da comunidade em políticas sociais. Saúde e Sociedade, São Paulo, v. 13, n. 2, p. 20-31, maio/ago. 2004.

GOMES, C. S. Desempenhos de desenvolvimento de municípios afetados por usinas hidrelétricas: um estudo de 4 usinas dos rios Pelotas, Canoas e Uruguai. 2014. 109 f. Tese (Doutorado em Ciências da Engenharia Ambiental) - Escola de Engenharia de São Carlos, Universidade de São Paulo, São Carlos, 2014. 
INSTITUTO BRASILEIRO DE GEOGRAFIA E ESTATÍSTICA (IBGE). Produto Interno Bruto dos Municípios. Disponível em: https://www.ibge.gov.br/estatisticasnovoportal/economicas/contas-nacionais/9088-produto-interno-bruto-dosmunicipios.html?edicao=18021\&t=downloads Acesso em: 18 dez. 2017.

INSTITUTO DE PESQUISA ECONÔMICA APLICADA (IPEA). Ipeadata regional: PIB municípios do Brasil: 1980-1996. Disponível em:

http://www.ipeadata.gov.br/Default.aspx Acesso em: 18 dez. 2017.

MINISTÉRIO PÚBLICO FEDERAL (MPF). Nota Técnica n. $^{\circ}$ 39: trabalho sobre área de influência. Brasília: MPF $/ 4^{\mathrm{a}}$ CCR; Escola Superior do Ministério Público da União, 2007.

MORAES, J. L. A. Capital social: potencialidades dos fatores locais e políticas públicas de desenvolvimento local-regional. In: BECKER, D. F.; WITTMANN, M. L. Desenvolvimento regional: abordagens interdisciplinares. 2. ed. Santa Cruz do Sul: EDUNISC, 2008. p. 263-281.

MORIN, E.; KERN, A.-B. Terra-Pátria. 5.ed. Porto Alegre: Sulina, 2005.

NUTI, M. R. Análise das estimativas de população atingida por projetos hidrelétricos. In: VERDUM, Ricardo (Org.). Integração, usinas hidrelétricas e impactos socioambientais. Brasília: INESC, 2007, p. 57-88.

PUTNAM, R. D. Comunidade e democracia: a experiência da Itália moderna. 5. ed. Rio de Janeiro: Editora FGV, 2006.

RAFFESTIN, C. Por uma geografia do poder. São Paulo: Ática, 1993.

REIS, M. J. Espaços vividos, migração compulsória, identidade: os camponeses do Alto Uruguai e a Hidrelétrica de Itá. 1998. 274 f. Tese (Doutorado em Ciências Sociais) - Instituto de Filosofia e Ciências Humanas, Universidade Estadual de Campinas, Campinas, 1998.

RIBEIRO, G. L. ¿Cuánto más grande mejor? Proyectos de gran escala: una forma de producción vinculada a la expansión de sistemas económicos. Desarrollo Económico, Buenos Aires, n. 105, v. 27, p. 3-27, abr./jun. 1987.

RIO GRANDE DO SUL. Decreto n. $^{\circ} 35.764$, de 28 de dezembro de 1994. Regulamenta a Lei $n^{\circ} 10.283$, de 17 de outubro de 1994, que criou os Conselhos Regionais de Desenvolvimento - CRDs. Diário Oficial, Porto Alegre, RS, 29 dez. 1994.

RIO GRANDE DO SUL. Lei n. ${ }^{\circ} 10.283$, de 17 de outubro de 1994. Dispõe sobre a criação, estruturação e funcionamento dos Conselhos Regionais de Desenvolvimento e dá outras providências. Diário Oficial, Porto Alegre, RS, 18 out. 1994. 
ROCHA, H. J. Integração desintegradora: a trajetória de projetos hidrelétricos desde a IIRSA até as comunidades locais. Mural Internacional, Rio de Janeiro, v. 3, p. 3036, 2012.

ROCHA, H. J. O controle do espaço-tempo nos processos de instalação de hidrelétricas. Tempo Social, São Paulo, v. 26, p. 259-280, 2014.

ROTHMAN, F. D. A emergência do movimento dos atingidos pelas barragens da bacia do rio Uruguai (1979-1983). In: NAVARRO, Z. (Org.). Política, protesto e cidadania no campo: as lutas sociais dos colonos e trabalhadores rurais no Rio Grande do Sul. Porto Alegre: UFRGS, 1996. p. 106-136.

SANTA CATARINA. Lei n. ${ }^{\circ} 16.795$, de 16 de dezembro de 2015. Dispõe sobre a transformação das Secretarias de Estado de Desenvolvimento Regional em Agências de Desenvolvimento Regional, extingue cargos e estabelece outras providências. Diário Oficial do Estado, Florianópolis, SC, 17 dez. 2015.

SANTOS, M. A natureza do espaço: técnica e tempo, razão e emoção. 4. ed. São Paulo: EDUSP, 2004.

SANTOS, M. Por uma outra globalização: do pensamento único à consciência universal. 12. ed. Rio de Janeiro/São Paulo: Record, 2005.

SANTOS, M. Técnica, Espaço, Tempo: globalização e meio técnico-científicoinformacional. 5. ed. São Paulo: EDUSP, 2008.

SEN, A. Desenvolvimento como liberdade. São Paulo: Companhia das Letras, 2010.

THOMPSON, E. P. Costumes em comum. São Paulo: Companhia das Letras, 1998.

VAINER, C. B. Planejamento territorial e projeto nacional: os desafios da fragmentação. Revista Brasileira de Estudos Urbanos e Regionais, Salvador, v. 9, n. 1, p. 9-23, 2007.

VAINER, C. B.; ARAÚJO, F. G. B. Grandes projetos hidrelétricos e desenvolvimento regional. Rio de Janeiro: CEDI, 1992.

Humberto Rocha. Professor Adjunto no Curso de Licenciatura em Ciências Sociais e no Mestrado em História da Universidade Federal da Fronteira Sul (UFFS).humberto.rocha@uffs.edu.br 
Como citar: ROCHA, Humberto. Hidrelétricas na Bacia do Uruguai e a promoção do Desenvolvimento Regional. Redes (St. Cruz Sul, Online), Santa Cruz do Sul, v. 25, n. 2, p. 696-720, maio 2020. ISSN 1982-6745. Disponível em:

https://online.unisc.br/seer/index.php/redes/article/view/9438 Acesso em: 15 maio 2020. doi: https://doi.org/10.17058/redes.v25i2.9438 